\title{
A Prospective Study of Prevalence and Nature of Psychiatric Patients Presented in Emergency Department of a Tertiary Care Teaching Hospital
}

\author{
Dishanter Goel \\ Associate Professor, Department of Psychiatry, \\ Teerthanker Mahaveer Medical College \& Research Centre, Moradabad, Uttar Pradesh, India.
}

\begin{abstract}
Background: More psychiatric visits, especially nonemergency ones, to emergency departments (EDs) of general hospitals have been observed in recent years. The aim of this study was to determine the characteristics of psychiatric visits to the ED of Teerthanker Mahaveer Medical College \& Research Centre.

Methods: In this cross-sectional study, during a two-month period, all psychiatric presentations and consultations to the ED of the studied hospital were included. The required data were gathered by psychiatry chief residents and were documented in pre-designed checklists.

Results: About $0.5 \%$ of all patients presenting to the ED needed the psychiatric visits. Men consisted $50 \%$ of the total patients with mean $( \pm S D)$ age of $38.41( \pm 14.7)$ years. About $51 \%$ of them had the indication of the emergency psychiatric visit while $47 \%$ had the indication of hospitalization in the psychiatric ward. Non-emergency visits were not related to demographic characteristic, previous psychiatric disorders, substance abuse and physical diseases.
\end{abstract}

Conclusions: Non-emergency visits take a high percentage of

\section{INTRODUCTION}

The number of psychiatric patients presenting to EDs has increased in different countries in recent years. Similarly, there has been a $38 \%$ increase in psychiatric visits to EDs in the US from 1992 to $2001 .{ }^{1}$ In addition; a study from National American College of Emergency Physicians demonstrated a 61.3\% increase in patients presenting to psychiatric emergencies EDs in a course of 6 to 12 months. ${ }^{2}$ Besides in other countries, psychiatric visits to EDs have increased due to an increase in the number of psychiatric units of general hospitals. ${ }^{3-5}$

Regarding this increase, many studies have been carried out about demographic characteristics, symptoms and disorders, the reasons of referrals and admission indications of mental health patients in EDs in many countries. ${ }^{6-9}$

As far as we know, there are few similar studies in our country about the percentage and characteristics of psychiatric visits to the EDs of general hospitals. In this study, the authors intended to investigate some characteristics of psychiatric visits to the ED of Teerthanker Mahaveer Medical College \& Research Centre, Moradabad, Uttar Pradesh, India. psychiatric visits in ED and regarding limited sources for psychiatric emergencies and Long visiting time, this percentage can hinder the process of giving services to real emergency psychiatric patients.

Key words: Emergency, Indication, Psychiatric visit.

\section{${ }^{*}$ Correspondence to:}

\section{Dr Dishanter Goel}

Associate Professor, Department of Psychiatry,

Teerthanker Mahaveer Medical College \& Research Centre, Moradabad, Uttar Pradesh, India.

\section{Article History:}

Received: 17-08-2016, Revised: 28-08-2016, Accepted: 07-09-2016

\begin{tabular}{|l|c|}
\hline \multicolumn{2}{|c|}{ Access this article online } \\
\hline $\begin{array}{l}\text { Website: } \\
\text { www.ijmrp.com }\end{array}$ & Quick Response code \\
\hline DOI: & \\
10.21276/ijmrp.2016.2.5.041 & \\
\hline
\end{tabular}

\section{MATERIALS AND METHODS}

In this cross-sectional prospective study, all emergency psychiatric visits to Teerthanker Mahaveer Medical College \& Research Centre in a four month period were studied. The data was collected by psychiatric chief residents, who had passed courses in diagnosing and treating emergency psychiatric problems, and recorded the required data inside pre-designed checklists made by the researchers. The data consisted of demographic characteristics, the time of request of visit, length of each visit, past history of psychiatric disorders, medical disease, substance abuse, emergency visit indication, need of hospitalization and its reason, need of revisiting and its reason and the process of discharging the patient. The information was gathered by interviewing the patient and their relatives and reviewing their files. The mean duration of information gathering time was 45 minutes. The emergency visit indication was determined based on clinical judgments of psychiatric residents and indications such as the danger of self-harm and harm to others, crisis encounter, symptoms of substance intoxication or 
withdrawal or treatment side-effects requiring immediate intervention. The need for hospitalization was also determined based on indications such as self-harm or harm to others, not responding to outpatient treatments, not having enough support or existence of environmental psychological stresses, especial treatment aims and judicial orders.

To analyze data, using the SPSS software for Windows (Version 15), and descriptive indices were used to express data and the student t-test and logistic regression were used to interpret data.

Table 1: Demographic features of mental health-related ED visits.

\begin{tabular}{lc}
\hline Variables & Frequency (\%) \\
\hline Marital status & \\
Married & $56(50.91)$ \\
Single & $47(42.73)$ \\
Divorced & $4(3.64)$ \\
Widow & $3(2.72)$ \\
Occupational status & \\
Employed & $44(40)$ \\
Unemployed & $66(60)$ \\
Educational status & \\
Illiterate & $2(1.82)$ \\
Primary education & $5(4.55)$ \\
Secondary education & $26(23.64)$ \\
High school before diploma & $53(48.18)$ \\
High school Diploma and college & $24(21.82)$ \\
\hline
\end{tabular}

\section{RESULTS}

In a course of 4 months, 102 psychiatric visits were done in the ED of Teerthanker Mahaveer Medical College \& Research Centre which was $0.5 \%$ of all visits to the ED of this hospital. There were 51 men (50\%) and 51 women (50\%). The average age of patients

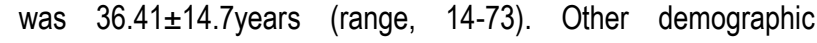
characteristics of patients such as marital status, occupation and educational level are shown in table 1.

Mean time of calling the resident and starting the visit was 14.6 \pm 5.9 minutes (range, $10-40$ minutes). Mean length of visiting time was $41.68 \pm 22.36$ minutes (range, 5-120).

Forty-six patients (45.1\%) had previously diagnosed by psychiatric disorders, 31 cases $(31.4 \%)$ had pervious or current substance abuse and 30 cases $(29.4 \%)$ had medical diseases.

Fifty-two patients (51\%) had indication of emergency psychiatric visit and the remainder (50 patients, 49\%) either came to the ED for non-emergency reasons or emergency physicians requested psychiatric consultation for non-emergency conditions. The frequency distribution of emergency visit indication based on other variables such as age, gender, educational level, and so on is shown in table 2.

Twenty-eight patients $(27.45 \%)$ were asked to present for a second visit, 9 patients (32\%) for further diagnostic investigations, 8 cases $(28.6 \%)$ with suspicion of having organic problems, 8 patients $(28.6 \%)$ for not having good conditions for the interview due to the low consciousness or emergency medical problems, and 3 patients (10.8\%) for other reasons.

Forty-eight patients $(47 \%)$ had indication to be hospitalized in psychiatric ward of the hospital (Table 3).

The need to be hospitalized had no significant statistical relationship with age $(p=0.024, d f=6)$, level of education $(p=0.866$, $d f=4)$, marital status $(p=0.2, d f=3)$, gender $(p=0.832, d f=1)$, and the current substance abuse $(p=0.426, d f=1)$. However, need for hospitalization showed significant relationship with occupation $(p<0.01, d f=1)$, medical disease $(p<0.01, d f=1)$, and pervious psychiatric disorders $(p<0.01, d f=1)$, in a way that more hospitalization indications were observed in unemployed people and patients with medical diseases or past history of psychiatric disorders compared to those who did not met these criteria. (Table 4)

Table 2: The frequency distribution of emergency visit indication based on other variables

\begin{tabular}{|c|c|c|c|c|}
\hline \multirow[t]{2}{*}{ Variables } & \multicolumn{2}{|c|}{ Indication of emergency psychiatric visit } & \multirow[b]{2}{*}{$P$ value } & \multirow[b]{2}{*}{ df } \\
\hline & Yes & No & & \\
\hline Gender (\%) & & & & 1 \\
\hline Female & $25(48 \%)$ & $26(52 \%)$ & 0.295 & \\
\hline Male & $27(52 \%)$ & $24(48 \%)$ & & \\
\hline Age: mean (SD) & $33.8 \pm 12.9$ & \pm 12.232 .2 & 0.166 & 6 \\
\hline Educational status & & & & 4 \\
\hline Illiterate & $0(0)$ & $1(1.89 \%)$ & & \\
\hline primary education & $2(3.8 \%)$ & $2(3.77 \%)$ & & \\
\hline secondary education & $16(29.09 \%)$ & $11(20.75 \%)$ & 0.706 & \\
\hline high school & $26(47.27 \%)$ & $27(50.94 \%)$ & & \\
\hline diploma and college & $12(21.82 \%)$ & $12(22.64 \%)$ & & \\
\hline Occupational status & & & & 1 \\
\hline Employed & $22(40 \%)$ & $23(43.40 \%)$ & 0.22 & \\
\hline Unemployed & $33(60 \%)$ & $30(56.60 \%)$ & & \\
\hline Marital status & & & & 3 \\
\hline Married & $27(49.09 \%)$ & $29(54.72 \%)$ & & \\
\hline Single & $24(43.64 \%)$ & $23(43.40 \%)$ & 0.528 & \\
\hline Divorced & $2(3.64 \%)$ & $1(1.89 \%)$ & & \\
\hline Widow & $2(3.64 \%)$ & & & \\
\hline Previous psychiatric disorders & $31(56.36 \%)$ & $17(32.8 \%)$ & 0.56 & 1 \\
\hline Previous or current substance abuse & $19(34.55 \%)$ & $13(24.53 \%)$ & 0.659 & 1 \\
\hline Comorbid medical Diseases & $14(27.27 \%)$ & $16(32.08 \%)$ & 0.2 & 1 \\
\hline
\end{tabular}


Table3: Indication of hospitalization and the reason of not hospitalizing

\begin{tabular}{lc}
\hline Variables & Frequency (\%) \\
\hline Indication of hospitalization & $29(60.42)$ \\
The risk of self-harm & $25(52.08)$ \\
The risk of harm to others & $15(31.25)$ \\
Not responding to outpatient treatments & $7(14.58)$ \\
Special treatment aims & $7(14.58)$ \\
Drug side effects (ex. NMS) & $3(6.25)$ \\
existence of environmental & psychological \\
stresses & $1(2.08)$ \\
Not having enough support & \\
Hospitalization & $33(66)$ \\
Yes & $17(34)$ \\
No & \\
The reason of not hospitalizing & $14(73.68)$ \\
Not having enough beds & $4(21.05)$ \\
Not having facilities & $1(5.26)$ \\
Family didn't consent to hospitalization &
\end{tabular}

Table 4: The frequency distribution of hospitalization indication based on other variables

\begin{tabular}{|c|c|c|c|c|}
\hline \multirow[t]{2}{*}{ Variables } & \multicolumn{4}{|c|}{ Indication of hospitalization } \\
\hline & Yes & No & $P$ value & df \\
\hline Gender (\%) & & & & 1 \\
\hline Male & $25(52.08)$ & $26(48.15)$ & 0.832 & \\
\hline Female & $23(48.92)$ & $28(51.85)$ & & \\
\hline Age: mean (SD) & $31.5(12.2)$ & $39.2(14.8)$ & 0.024 & 6 \\
\hline Educational status & & & & 4 \\
\hline Illiterate & $0(0)$ & $1(1.85)$ & & \\
\hline primary education & $3(6.25)$ & $1(1.85)$ & & \\
\hline secondary education & $12(25)$ & $13(24.07)$ & 0.866 & \\
\hline high school & $24(50)$ & $26(48.15)$ & & \\
\hline diploma and college & $9(18.75)$ & $13(24.07)$ & & \\
\hline Occupational status & & & & 1 \\
\hline Employed & $14(29.17)$ & $28(51.85)$ & 0.01 & \\
\hline Unemployed & $34(70.83)$ & $26(48.15)$ & & \\
\hline Marital status & & & & 3 \\
\hline Married & $23(47.92)$ & $29(53.70)$ & & \\
\hline Single & $22(45.83)$ & $23(42.6)$ & 0.2 & \\
\hline Divorced & $2(4.17)$ & $1(1.85)$ & & \\
\hline Widow & $1(2.08)$ & $1(1.85)$ & & \\
\hline Previous psychiatric disorders & $30(62.5)$ & $16(29.63)$ & 0.002 & 1 \\
\hline Previous or current substance abuse & $17(35.42)$ & $14(25.92)$ & 0.426 & 1 \\
\hline
\end{tabular}

\section{DISCUSSION}

The present study showed that of all emergency visits, $0.5 \%$ was due to psychiatric reasons which is much less than reported figures from other countries which is between 2 and $2.5 \%$. The reason for this considerable difference is not related to number of psychiatric visits because in other countries the average visits was between 60-90 people per month in comparison with the 50 people in our study. However the real reason maybe is the great number of visitors to the ED of the Teerthanker Mahaveer Medical College \& Research Centre as a major hospital in Moradabad. In this study, only $51 \%$ of patients had the indication of emergency psychiatric visit. It is very common to see non-urgent use of EDs in many parts of the world and all medical fields and it is reported that such visits take $85-95 \%$ of visits. Surprisingly, outpatient visits had a 50\% increase from 1955 to 1970 , whereas emergency visits increased by $312 \%$ in the same period in the US. ${ }^{10}$ Although $52 \%$ is more heartwarming than $85-95 \%$ for non-urgent medical visits in EDs in other countries, regarding limited sources for psychiatric emergencies, long visiting times (which was in average 42 minutes in this study) and the need to have special facilities for such visits, this percentage can still hinder the process of giving services to real emergency psychiatric patients. ${ }^{11}$

In this study, no demographic characteristics were related to nonemergency visits to the ED. Results of most studies about the gender of non-emergency visits to emergency wards are different. Some, like the present study, showed no difference between genders ${ }^{12,13}$ and some have suggested that it is more common in men or in women. ${ }^{14,15}$ Unlike the probability of having more visits from the older patients, in this and most studies, the age range of patients was between 20 and 40 years of age which is in accordance with the age range of all visitors to the EDs. ${ }^{12,13}$ In some studies it is reported that having low social support, living alone and being single are related to non-urgent use of EDs. ${ }^{16,17}$ However, in this study, marital status was not related to this issue 
which is probably because of the fact that in our country the immediate family consisting father, mother and siblings is still a very important provider of support, and being single does not necessarily show isolation and lack of social support. It is clear that carrying out studies with more samples with the aim of analyzing social support with special questionnaires can clarify the relation between social support and non-urgent use of EDs. In this study, job status as a mark of economic status was not in any relation with non-emergency psychiatric visits in the ED. Although some studies have shown economic status to be related to nonurgent use of EDs, race influences this relation. As was seen, economic status in whites has a reverse relation with nonemergency visits in ED, but for blacks economic conditions are not in any relation to non-emergency visits. ${ }^{12,18}$ On the one hand, poverty and being covered by insurance are the benefits of emergency service especially for unemployed people with poor economic status. On the other hand, its being 24 hours has made it available for the people who work and cannot go to outpatient centers during the day.

Some of these visits may be requested by emergency physicians for medical patients, with non-urgent psychiatric signs and symptoms and even $28.6 \%$ of needs to revisits were due to the unsuitable level of consciousness or the existence of medical emergencies. This emphasizes the impotence of increasing coordination and cooperation between emergency physicians and psychiatrists to reduce time and expenses. Furthermore, medical professionals and patients may differ in what they assume as a medical emergency is. ${ }^{19}$ This also may be true for emergency psychiatric situations and having more studies about public attitude to emergency psychiatric problem could be useful.

In this study, $47 \%$ of patients needed to be hospitalized which is very close to western countries. ${ }^{20}$ In this study, $75 \%$ of patients were not hospitalized due to insufficient beds and $18.7 \%$ for not having essential facilities like isolation room for aggressive patients which is high percentage.

The limitations of this study must be mentioned. First we did not evaluate some important variables like economic status and support system. Second, our sample was not large enough. Future studies should address these issues in larger sample sizes.

\section{REFERENCES}

1. Larkin GL, Claassen CA, Emond JA, Pelletier AJ, Camargo CA. Trends in US emergency department visits for mental health conditions, 1992 to 2001.PsychiatrServ 2005; 56(6): 671-7.

2. Boudreaux E. D, Allen M.H, Claassen C, Currier G.W, Bertman L, Glick R, Park J, Feifel D, Camargo C.A. The Psychiatric emergency research collaboration: methods and results. Gen Hosp Psychiatry 2009; 31(6): 515-22.

3. McDonough S, Wynaden D, Finn M, McGowan S, Chapman R, Hood S.Emergency Department mental health triage consultancy service; an evaluation of the first year of the service. Accid Emerg Nurs 2004;12(1):31-8.

4. Summers M, Happell B. Patient satisfaction with psychiatric services provided by a Melbourne tertiary hospital emergency department. J Psychiatr Ment Health Nurs 2003; 10 (3): 351-7.

5. Hundertmark J. The impact of mainstreaming on patient care in Australian emergency departments and liaison services. Aust N Z J Psychiatry. 2002 Jun; 36(3):424.
6. Smith RP, Larkin GL, Southwick SM. Trends in US emergency department visits for anxiety-related mental health conditions, 1992-2001. J Clin Psychiatry. 2008; 69(2):286-94.

7. Larkin GL, Smith RP, Beautrais AL. Trends in US emergency department visits for suicide attempts, 1992-2001.Crisis.2008; 29(2):73-80.

8. Fry M, Brunero $\mathrm{S}$. The characteristics and outcomes of mental health patients presenting to an emergency department over a twelve month period. Aust Emerg Nurs 2004; 7(2):21-5.

9. Pandya A, Larkin GL, Randles R, Beautrais AL, Smith RP. Epidemiological trends in psychosis-related Emergency Department visits in the United States, 1992- 2001.Schizophre Res 2009;110(1-3):28-32.

10. Petrich FA, House MA. Improved data generation needed for ambulatory planning. Hosp Prog 1973;54(11):84-6.

11. NAMI Newsroom. Emergency Departments see dramatic increase in people with mental illness seeking care. [Cited 2004 April 27]. Available from: URL: http://www.nami.org

12. Torrens PR, Yedvab DG. Variations among emergency room populations: a comparison of four hospitals in New York City. Med Care 1970; 8(1):60-75.

13. Genell Andrén K, Rosenqvist U. Heavy users of an emergency department-a two- year follow up study. Soc Sci Med 1987; 25(7):825-31.

14. Stain DG. The hospital emergency unit patient and his presenting picture. Med Care 1973; 11(4):328-37.

15. Berman JI, Luck E. Emergency services: patients' ethnic backgrounds affect utilization. Hospitals 1971; 45 (14): 64-8.

16. McKinlay JB. Social networks, lay consultation and helpseeking behavior. Socforces 1971; 51(3): 275-92.

17. Horwitz SM, Morgenstem H, Berkman LF. The impact of social stressors and social networks on pediatric medical care use. Med Care 1985; 23(8): 946-52.

18. White-Means SI, Thornton MC. Nonemergency visits to hospital emergency rooms: a comparison of blacks and whites. Milbank Q. 1989; 67(1):35-57.

19. Wolcott BW. What is an emergency? Depends on whom you ask. JACEP 19798(6):241-3.

20. Sadock BJ, Sadock VA. Synopsis of psychiatry. Philadelphia: Lippincott William \& Wilkins; 2007. p. 887.

\section{Source of Support: Nil.}

\section{Conflict of Interest: None Declared.}

Copyright: (๑) the author(s) and publisher. IJMRP is an official publication of Ibn Sina Academy of Medieval Medicine \& Sciences, registered in 2001 under Indian Trusts Act, 1882.

This is an open access article distributed under the terms of the Creative Commons Attribution Non-commercial License, which permits unrestricted non-commercial use, distribution, and reproduction in any medium, provided the original work is properly cited.

Cite this article as: Dishanter Goel. A Prospective Study of Prevalence and Nature of Psychiatric Patients Presented in Emergency Department of a Tertiary Care Teaching Hospital. Int J Med Res Prof. 2016; 2(5):196-99. 